\title{
Lo kafkiano en clave histórica: para una lectura crítica de "la metamorfosis'"
}

La obra de Kafka es una elipse cuyos focos, muy alejados el uno del otro, están determinados de un lado por la experiencia mistica (que es sobre todo la experiencia de la tradición) y de otro por la experiencia del hombre moderno de la gran ciudad

Walter Benjamin 2

$\mathrm{E}$ scrita en 1912 y publicada tres años después, "La Metamorfosis" es una de las obras más comentadas y debatidas de la literatura del siglo veinte. Algunos críticos sostienen que este relato largo es una transposición literaria de los conflictos familiares del autor. Indudablemente, Kafka partió de aspectos de su experiencia personal. Así lo afirma su amigo Gustav Janouch, a quien el autor confesó su insatisfacción sobre la obra, la cual le parecía un acto de indiscreción imperdonable: habría allí aspectos de su vida íntima que se arrepentía de haber expuesto ante los lectores. Sin embargo, esta constatación no debe llevarnos creer que el potencial significativo de "La Metamorfosis" se agote en el aspecto biográfico. Todo artista parte en primera instancia de sus experiencias, que igual pueden ser propias o compartidas. Sin embargo, para que su obra tenga valor e importancia, debe ser capaz de trascender esas circunstancias y elevarlas a una dimensión más universal, de su época o si se quiere (hoy en día suena arriesgado afirmarlo) de la condición humana.

El presente trabajo no pretende establecer de manera definitiva lo que Kafka 'quiso decir' en "La Metamorfosis". Tarea vana para toda obra literaria, la cual 
es siempre capaz de soportar diversas lecturas, pero sobre todo para un escritor de la talla de Kafka quien ha dado lugar a montañas de interpretaciones por parte de entendidos mucho más eruditos e inteligentes que quien escribe estas líneas. Aquí sólo se pretenden dos cosas. En primer lugar, situar al autor y su obra en una serie de contextos, los cuales enriquecerán nuestra lectura en alguna medida. A través de un esbozo de estos contextos -personales, sociales, culturales- se reinserta la obra en sus múltiples y complejas determinaciones. En segundo lugar, se resaltan algunos elementos importantes del texto de "La Metamorfosis" que puedan ayudarnos a comprender mejor su funcionamiento y a formularle preguntas interesantes. Recordemos que una obra literaria no es un objeto inerte que se disecta y describe, sino un verdadero interlocutor, la voz de un autor con una visión privilegiada sobre su circunstancia vital, pero también la voz de otros tiempos que puede ayudarnos a iluminar nuestra realidad.

\section{I}

De los contextos

En las siguientes líneas me interesa demostrar que el mundo 'kafkiano', presente tanto en "La Metamorfosis" como en el resto de una obra que presenta una sorprendente unidad, no es una invención fortuita. Este mundo imaginario gris, poblado de seres débiles y anodinos, sometidos a fuerzas obscuras, a la vez arbitrarias y enigmáticas, no está desligado del mundo concreto que le tocó vivir a Franz Kafka. No se trata ciertamente de un reflejo mecánico simple, sino más bien de una 'imagen en negativo', que necesita de la participación del lector inteligente para revelar dimensiones de la realidad imposibles de ser captadas 'en positivo'. Este universo imaginario, que podrá parecer irreal o absurdo, se entenderá mejor si examinamos algunos de los contextos que rodearon la creación de obras como El Proceso, "La Condena", El Castillo o "La Metamorfosis".

Franz Kafka nació un tres de julio de 1883 en la ciudad de Praga -capital de la actual República Checa mas, por ese entonces, capital del Reino de Bohemia del Imperio Austro-Húngaro- en el seno de una familia que pertenecía a la minoría judía germanohablante. Estos datos ya apuntan a circunstancias que rodearán la actividad creativa de nuestro autor. En primer lugar, Kafka nace el mismo año de la muerte de Karl Marx, filósofo cuya obra fue uno de los pilares del movimiento socialista y comunista. Esto no es irrelevante porque las consecuencias de estos movimientos dejarían una marca indeleble el mundo en que Kafka creció y se desarrolló como artista. El lugar de nacimiento tampoco es gratuito. La posición periférica de Praga con respecto al centro político del imperio austrohúngaro y a los centros de la literatura y cultura alemana de ese entonces, Berlín y Viena, le darán a nuestro autor una relación muy importante 
con respecto a la lengua y la identidad nacional. Finalmente, esto último se verá todavía más complicado al tener en cuenta el origen judío de Kafka, así como su calidad de germanohablante en una ciudad donde el idioma más difundido era el checo.

\section{Una vida sin atributos}

Nada más lejos de lo singular y heroico que la vida de Franz Kafka. De haber seguido su amigo Max Brod las instrucciones de destruir sus manuscritos después de su muerte, Kafka sería a lo más conocido como un obscuro funcionario del imperio austrohúngaro que publicó unas cuantas narraciones, entre ellas "La Metamorfosis". El grueso de su obra, especialmente su trilogía novelística de América, El Proceso y El Castillo, fueron publicados póstumamente. En resumen, Kafka no fue un autor reconocido en vida. Tampoco se dedicó profesionalmente a la Literatura, pese a que en sus Diarios confesaba: "no tengo intereses literarios, sino que estoy hecho de Literatura, no soy nada más y no puedo ser nada más"3.

La vida de Kafka estuvo marcada por varios conflictos que harían de su vida una tribulación constante, muy similar a la sufrida por los personajes de sus obras. Entre los conflictos más sobresalientes habría que resaltar la compleja relación con su padre, la imposibilidad por optar por una carrera literaria y la incapacidad de establecer una relación amorosa duradera.

En el primer caso, la vida de Franz Kafka quedaría profundamente marcada por su padre. Hermann Kafka era un hombre que había alcanzado cierta posición social y una fortuna de alguna consideración por su propio esfuerzo y pese a no haber recibido una educación notoria. Franz, su primogénito y único hijo varón, sentía hacia su padre una compleja mezcla de admiración y temor. Admiraba su voluntad, su disciplina, su fuerza física; pero temía sus frecuentes accesos de ira, su inquebrantable seguridad en sí mismo y sus arranques de arbitrariedad. De niño, Franz buscaba refugio y protección en su madre, Julie Löwy, quien lo fue iniciando en el mundo de la lectura y la música.

Ya adulto, Franz se sintió incapaz y poco motivado para seguir el camino de su padre y tomar las riendas del negocio familiar. Sabiéndose también incapaz de ganarse la vida como escritor, buscó una solución de compromiso: un cargo público que le retribuyera buenos ingresos, respetabilidad social y tiempo libre para escribir. De aquí deriva el segundo conflicto. Kafka había recibido una educación muy esmerada, la educación propia de las élites del imperio. Estudió Derecho con la esperanza de poder conseguir un trabajo que le permitiera ingresos decorosos y tiempo para dedicarse a la Literatura. Desde adolescente Kafka había mostrado vocación hacia la Literatura. Era un gran lector y seguía, tanto como fuera posible desde Praga, el acontecer cultural europeo. Frecưentaba los 
círculos de escritores, donde trabó relación intelectual con autores como Max Brod y Gustav Meyring. Sin embargo, al cabo de los años, Kafka se da cuenta de que su anhelo de poder combinar un trabajo respetable con su vocación literaria resulta sumamente difícil. Padece una gran frustración por no poder dedicarse en cuerpo y alma a su pasión: escribir. Se cree que la enfermedad que acabaría tempranamente con su vida (a los cuarenta años) se desarrolló en parte del exceso de trabajo. En los momentos más duros de su vida, dedicaba una jornada de ocho horas a su trabajo y otras tantas a escribir.

Además de lo anterior hay que agregar que la vida amorosa de Kafka tampoco fue especialmente feliz. Algunos de sus biógrafos señalan cierta dificultad edípica de separarse del núcleo familiar. Kafka mantuvo noviazgo, hasta cierto punto bajo presión familiar con Felice Bauer. A pesar de varios compromisos, rupturas y conciliaciones, el matrimonio jamás llegó a efectuarse. Algo similar, aunque por menos tiempo, le pasó con Julie Wohrycek. Luego mantuvo Kafka una relación con la escritora y activista checa Milena Jenseská-Pollak. Sólo será hasta el final de su vida, que vivirá con la mujer a quien ama, en este caso, Dora Dymant quien le acompaño hasta su muerte.

Cabe resaltar que los elementos antes esbozados del drama familiar de Kafka pueblan su obra. Recordemos que sobre los hombros de Gregor Samsa, el protagonista de La Metamorfosis, pesará una deuda familiar impagable. Enfrentar el reproche paterno llevará al personaje de "La Condena" al suicidio. Por otro lado, personajes como José K. en El Proceso o K. en El Castillo se ven envueltos en relaciones con mujeres cuyas consecuencias son incapaces de controlar o asumir. De haber sido esto una circunstancia meramente personal de Kafka, todo lo anterior caería totalmente totalmente dentro de la psicopatología. Sin embargo, ¿l drama de Kafka como veremos más a continuación, está relacionado con otros problemas que trascienden el ámbito individual o familiar.

\section{La era del capitalismo burocrático}

Una mediación sumamente importante para entender a Kafka tiene que ver con el conflictivo período de la historia Europea que le tocó vivir. Hablábamos hace poco de la coincidencia entre la fecha de nacimiento de Kafka y la de la muerte de Karl Marx. Este último al estudiar a fondo el capitalismo liberal en expansión de su época había llegado a la conclusión de que sus días estaban contados. Este sistema habría llegado a acumular tales contradicciones que sus crisis cíclicas se volverían permanentes hasta provocar una revolución social que llevaría al poder un régimen proletario. Sin embargo, y pese al efecto que tuvieron los escritos de Marx en alimentar el movimiento socialista, sus predicciones no resultaron ciertas. En buena parte, el desatino se debió a que Marx no anticipó que el sistema diseñaría medidas para controlar y distender sus crisis. 
El control de las crisis se lograría, en buena parte, a través de un incremento de la participación del Estado en el ámbito económico y en el social. En el primer caso el Estado incrementaría las regulaciones así como su participación directa en sectores claves de la economía: las finanzas, la construcción de la infraestructura, ciertos sectores de las comunicaciones (correos, telégrafos, ferrocarriles), etc... En el ámbito social, por otra parte, el Estado diseñó políticas destinadas resolver "la cuestión social", es decir en prevenir precisamente lo que Marx y sus compañeros anticipaban: una cataclismo de grandes proporciones que marcase el fin de la era de la burguesía. Si bien en algunos países europeos, especialmente en aquellos donde sus instituciones democráticas estaban menos solidificadas, el Estado recurrió al ejercicio de la violencia y la coerción para desarticular los movimientos de trabajadores; este no fue el método más frecuente y, mucho menos, el más efectivo. Los Estados tuvieron que diseñar una serie de estrategias con el objetivo de corregir los desequilibrios que el sistema capitalista de mercado generaba e integrar los grupos conflictivos y heterogéneos que los conformaban a la 'nación'. Por un lado, se experimenta un incremento significativo en el sistema educativo. Esto posibilita tanto una cierta homogenización de la población como la difusión de ideologías nacionalistas que representaban al Estado como el representante legítimo de los intereses del conglomerado social. Por otro lado, tienen lugar a una serie de medidas que, posteriormente, darán lugar a la concepción de Estado de Bienestar. Poco a poco, el Estado distiende los conflictos sociales al asumir, en tanto representante del colectivo nacional, la provisión de ciertos servicios de salud, el amparo a los indigentes, el otorgamiento de pensiones a los ancianos, etc... De hecho, Franz Kafka trabajaría la mayor parte de su vida en la "Compañía de Seguros de Accidentes de Trabajo", una rama de la incipiente Seguridad Social del imperio austro-húngaro.

Independientemente de su efectividad inmediata, lo que trajo este movimiento fue un crecimiento sin precedentes del aparato administrativo estatal. Esta situación fue aún más acentuada en países relativamente 'atrasados' como Alemania, el imperio Austro-Húngaro y el imperio Ruso donde la modernización de las estructuras debía ser inducida 'desde arriba', es decir donde el Estado debía de jugar un papel no sólo en la regulación de los efectos del capitalismo sino en la expansión de sus propias economías. Por otra parte, los aparatos burocráticos de estos países ya eran de por sí grandes y moldeados menos sobre la base de las democracias liberales de Europa Occidental que sobre las estructuras caducas de la monarquía absolutista.

La mayoría de los aspectos arriba esbozados no aparecen de manera explícita en la obra de Kafka, con excepción del último: la expansión de la burocracia y su manera de pensar y operar es la mediación social más palpable en la obra de Kafka. El mundo 'kafkiano' está poblado de funcionarios, de abogados, de papeleo, de reglas incomprensibles, de decisiones arbitrarias, en fin, de individuos 
reducidos a su mínima expresión, a objetos manipulables y descartables de una máquina incontrolable.

No hay que olvidar que la burocracia del imperio austro-húngaro además de presentar rasgos típicos de toda organización burocrática -impersonalidad, jerarquía, papeleo, etc...- tenía un carácter bastante peculiar, propio del régimen autoritario y obsoleto que la había formado. Era pues una organización poco transparente en la cual las reglas y las decisiones más importantes estaban en manos de los renglones superiores de la jerarquía y jamás descendían hasta abajo. De allí la sensación de estar a merced de fuerzas ineluctables que prevalece en el mundo kafkiano. Veamos el testimonio de uno de los apuntes literarios de Kafka:

"En general nuestras leyes no son conocidas, sino que constituyen un secreto del pequeño grupo de aristócratas que nos gobiema. Aunque estamos convencidos de que estas antiguas leyes son cumplidas con exactitud resulta en extremo mortificante el verse regidos por leyes por uno desconocidas". 4

Kafka conoció la vida burocrática desde dentro. Perteneció a una generación de jóvenes de la élite cuyos padres habían ascendido socialmente como comerciantes y empresarios independientes. Sin embargo, estos jóvenes ingresaron al aparato burocrático para asegurar la posición alcanzada por sus progenitores. Educados para ser almas libres, entraron a un juego donde lo que se premiaba era la sumisión y las lealtades irracionales. Ante este prospecto gris de existencia, no es de extrañar que el mundo de la Literatura y la Cultura ofreciera la posibilidad de redención. Se explica así la pasión de nuestro autor por la Literatura, pero también las dificultades de abandonar el cargo que desempeñaba.

No hay que dejar de mencionar, que la óptica de Franz Kafka no es la de un funcionario mediocre y resentido por su escaso éxito. Kafka era un tipo dotado de gran inteligencia y capacidad de trabajo. Su trayectoria en la Compañía fue exitosa y fue ascendiendo en la escala jerárquica hasta alcanzar puestos ejecutivos de responsabilidad. Aún así, repetidas veces y en repetidos lugares manifiesta que detesta profundamente su trabajo. No sólo lo detesta porque lo distrae de su verdadera vocación; también da testimonio de la miseria y la degradación humana que debía presenciar cotidianamente. La vista de personas negadas de su dignidad por una maquinaria prepotente e insensible le ofendía profundamente.

La burocracia o mejor dicho la sociedad regida por una racionalidad burocrática donde la libertad y creatividad humana son asfixiadas es la cárcel del alma humana que Kafka vivió y recreó en su obra. José María González García, filósofo y sociólogo español, ha establecido paralelos entre Franz Kafka y Max Weber, padre de la ciencia sociológica, quien fuera su contemporáneo. Weber empleó la metáfora del ser humano aprisionado por una jaula de hierro para explicar teóricamente la dinámica del capitalismo tardío y su tendencia a la burocratización. 
Esta capacidad de Kafka para captar el lado siniestro de la mentalidad burocrática lo llevó a trascender su propia época y de proveer imágenes de la pesadilla kafkiana hecha realidad poco tiempo después. Me refiero al nazismo, donde el exterminio de seres humanos (entre ellos seis millones de judíos, y entre estos las tres hermanas de Kafka) se realizó con la frialdad y pulcritud de un proyecto gubernamental eficientemente planificado. Me refiero también al llamado socialismo real de la Ex-Unión Soviética y Europa del Este donde la racionalidad burocrática llevada a su culminación transformó el ideal socialista de libertad con igualdad en una pesadilla de corrupción, escasez, trabajos forzados y vigilancia policial. Sin proponérselo, los escritos de Kafka no sólo tuvieron un valor analítico de la realidad de su tiempo, sino también un valor profético al vislumbrar la culminación de las males que alcanzó a detectar.

\section{Un laberinto de nacionalidades}

Como dijimos al principio, Praga no fue durante la mayor parte de la vida de Kafka la capital de la nación Checa. Resulta, por lo tanto, inexacto afirmar que Kafka es un escritor checo, como también lo sería decir que es un escritor austríaco o alemán. Más adelante veremos el problema de la identidad nacional y cultural de la obra de Franz Kafka, por el momento nos interesa hacer un esbozo de la compleja situación en la que vino al mundo.

Praga era por ese entonces la capital del reino de Bohernia, uno de las tantas entidades que formaban el Imperio Austro-Húngaro gobernado por el emperador Francisco José I, monarca de la dinastía de los Habsburgo. Definir la nacionalidad del imperio austríaco resultaría complicado. Más aún, fue precisamente la emergencia de los nacionalismos durante el siglo pasado lo que acabó socavando a este singular imperio, encabezado por los Habsburgo -familia noble de origen alemán- quienes debían reinar sobre súbditos de lengua alemana, checa, húngara, polaca, ucraniana, eslovena, serbocroata, por mencionar algunas. Está por demás decir que ninguna de estas etnias era mayoritaria. Al optar la dinastía imperial, hacia fines del siglo XVIII por reivindicar sus raíces alemanas, dará una estocada mortal a la legitimidad de su gobierno sobre los habitantes de otras nacionalidades, quienes constituían la mayoría de la población y habitaban la mayor parte del territorio. No es casualidad que de allí hayan surgido un gran número de estados nacionales en años posteriores. Entre ellos basta mencionar a Austria, Hungría, la República Checa, Eslovaquia, Eslovenia, Croacia, BosniaHerzegovina, por no incluir partes de las actuales Italia, Polonia y más de alguna de las ex-repúblicas soviéticas. Robert Musil, escritor contemporáneo de Kafka y también habitante del Imperio Autro-Húngaro, nos da un vivo testimonio de esta complicada situación: 
"Este concepto de la nacionalidad austro-húngara estaba de tal manera formulado que es casi inútil intentar explicarlo a quien no lo haya adquirido por propia experiencia. No estaba constituido de una parte austríaca y otra húngara que, como se podía creer, se complementaban entre sí y formaban un todo, sino que lo componían un todo y una parte, o sea, el concepto de Estado húngaro y el otro concepto de Estado austro-húngaro; este último tenía su morada en Austria, mientras que el concepto de nacionalidad austríaca carecía de patria. El austríaco existía sólo en Hungría, y allí, bajo la forma de aversión; en casa se llamaba a sí mismo súbdito de los reinos y países de la Monarquía austro-húngara representados en la Cámara, lo cual significaba tanto como declararse austríaco-más-unhúngaro-menos-este-húngaro, y no lo haría por entusiasmo, sino por amor a una idea que le repugnaba, pues no podía soportar a los húngaros como tampoco los húngaros a él; así es que el asunto se complicaba más todavía. Muchos se llamaban por eso polacos, checos, eslovenos o alemanes a secas, lo cual producía ulteriores divisiones" 5

Dentro de este abigarrado mosaico, la situación de Kafka presenta una complejidad adicional: su orígen judío. Los judíos del imperio austrohúngaro acaso no se contaban entre los sectores menos desaventajados desde el punto de vista económico, sin embargo, su posición era bastante precaria en otros sentidos. En primer lugar, los judíos cargaban consigo una vieja historia de persecución y discriminación. Por no profesar la religión cristiana en un continente donde, por siglos, esta había sido la principal fuente de integración social, los judíos eran vistos con suspicacia por todos los otros grupos además de padecer de limitaciones legales a sus derechos. Para citar un caso, en Austria-Hungría y Alemania, los judíos por ley no podían acceder a puestos públicos hasta bien entrado el siglo XX. Cuando estuvieron, finalmente, facultados para hacerlo sufrían de trabas e impedimentos. Kafka pudo entrar al servicio público gracias a la protección de un amigo de la familia, poderoso e influyente. En segundo lugar, pesaba sobre los judíos un peligro aún mayor. Por no tener ningún reclamo territorial de origen en el Imperio, eran vistos como foráneos por todos los grupos, y fácilmente se convertían en el chivo expiatorio de las causas nacionalistas de cualquier bando. De hecho, tanto el nacionalismo checo como el nacionalismo austroalemán eran marcadamente antisemitas.

Ahora bien, por el hecho de ser judío podríamos creer que Kafka podía apelar a una identidad y tradición cultural propias. Sin embargo, la cuestión no es tan simple. Kafka pertenecía a un considerable número de comunidades judías que se habían asimilado exitosamente a la cultura germánica. Kafka era uno de los cerca de 30,000 habitantes de Praga que empleaban el alemán como primera lengua. Además había recibido una esmerada educación en instituciones educativas alemanas. Sobra decir que dominaba esa lengua a la perfección y conocía a fondo su literatura. Ello tenía indudables ventajas en una región donde el alemán era la lengua de la administración pública. Sin embargo, en la medida 
que la cuestión nacional se tornaba más álgida y el antisemitismo más furioso, se clausuraba la posibilidad de los judíos germanizados de considerarse verdaderamente alemanes. De maneras pocos sutiles sus enemigos solían recordarles que eran 'diferentes'.

Como reacción defensiva hacia una hostilidad que llevaría durante la Segunda Guerra Mundial al aniquilamiento de la mitad de la población hebrea de Europa, algunos judíos comenzaron a idear su propio nacionalismo. La expresión más importante de esta tendencia es el sionismo que comienza a consolidarse como ideología aglutinadora de los judíos europeos desde mediados del siglo $\mathrm{XIX}^{6}$. Este movimiento se proponía unir a las comunidades judías dispersas en diversas latitudes del globo en torno a una recuperación de las 'raíces' culturales y al proyecto de crear un estado nacional judío, Israel, en la remota Palestina. Palestina había sido la tierra prometida desde tiempos bíblicos, pero a finales del siglo XIX era una provincia del Imperio Otomano, habitada por musulmanes, cristianos y judíos. Kafka participó del entusiasmo de su generación por redescubrir las raíces olvidadas de su pueblo. Sin embargo, a diferencia de su amigo Max Brod, nunca llegó a militar activamente en la causa sionista. Kafka tenía sospechas de que el sionismo reprodujera muchos de los vicios de otros nacionalismos. Además, en el fondo, su inclinación era quizá demasiado cosmopolita para sentirse cómodo dentro de una sola identidad. Recordemos que Kafka además de ser versado en la cultura germana y a través de ella en los clásicos occidentales, hablaba y escribía checo (la lengua de la mayoría de la población de su ciudad) a la perfección, y había estudiado hebreo. Sin renegar de sus raíces judaicas, Kafka se sintió más cómodo en el cruce de varias culturas. Y será el enfrentamiento entre su mundanidad moderna con la tradición judaica la que se mostrará más fructífera en su creación literaria.

Nuevas ideas: socialismo, anarquismo y psicoanálisis

Pese a que la imagen que se nos ha transmitido de Kafka es la de un ser aislado en su estudio o en su oficina, la verdad es que los testimonios confirman que no fue ajeno ni a la política ni al intenso movimiento cultural de su época. Antes mencionamos su gravitación alrededor del movimiento sionista. Sin embargo, sus simpatías no quedaban allí. Los años de la juventud de Kafka son de una intensa conmoción política. No sólo existían los movimientos nacionalistas, sino también otros movimientos que reclamaban, más que un estado nacional propio, la re-estructuración de la sociedad sobre bases enteramente nuevas. Entre estos grupos sobresalían los socialistas y los anarquistas. Aunque distaba de ser un movimiento compacto y homogéneo, el socialismo abogaba por la propiedad social de los medios de producción y por la constitución de un Estado liderado por los trabajadores. Regímenes monárquicos como el austro-húngaro les parecían arcaísmos inaceptables, pero además denunciaban a las democracias 
liberales de los países más avanzados como mascaradas políticas donde se continuaba la explotación del hombre por el hombre.

Aunque hay testimonios de cierta simpatía de Kafka por el movimiento obrero y de su participación en actos realizados por organizaciones socialistas, parece ser que nuestro autor era mucho más afín hacia las tendencias anarquistas. Para el anarquismo, toda forma de organización estatal en la política e industrial en la economía era contraria a los anhelos de libertad del hombre. Los anarquistas propugnaban la destrucción del estado y la formación de comunidades igualitarias donde se extirpara cualquier forma de dominación. Kafka fue al parecer muy asiduo lector de Otto Gross, un anarquista que frecuentó la obra de Freud? ${ }^{7}$. Para Gross, lo que había que combatir era el principio patriarcal de organización social, presente desde la familia hasta las formas más complejas y organizadas de poder. La desigualdad emanaba de este principio patriarcal y para combatirlo, Gross sostenía que había que reorganizar la sociedad sobre principios más cercanos al principio maternal que da calor y protección a todos por igual. Es de esperar que estas ideas harían resonancia en Kafka no sólo por sus simpatías políticas sino por su peculiar situación familiar.

Gross y su peculiar propuesta es parte de un clima intelectual mucho más amplio y complejo que impregnaba el medio cultural en que nuestro autor se desarrollaba intelectualmente. Además de Freud, Marx y los pensadores anarquistas, otra figura importante era el filósofo alemán Friedrich Nietzsche, crítico visceral de la era moderna, para quien la Cultura Occidental y su tradición humanismo conducían irremisiblemente a la degradación del hombre en su ser débil y desprovisto de voluntad. Ante esto, Nietzsche proponía un retorno a las fuentes irracionales de las culturas antiguas donde lo que predominaba era la acción y la voluntad de dominio. Sólo así, podría Occidente salvarse de la irremisible decadencia a la que se encontraba destinado.

En todos los autores que hemos señalado arriba parece haber un denominador común: la creciente suspicacia en el individuo como ente racional y en dominio de sí mismo y su circunstancia. Esta fe había sido fundamental durante la transformación que sufriera Europa en los siglos XVIII y XIX. Sin embargo, en la época de Kafka este optimismo parece haberse evaporado. El individuo racional, defendido por la cultura de occidente como el principio sobre el que habría de edificarse una nueva era de progreso, se descubre como alguien extraño a sí mismo. Freud mostrará que ese individuo nunca estará en control de fuerzas inconscientes impelidas por su propia naturaleza y por un orden social que le es impuesto a la fuerza. Nietzsche pretenderá demostrar que detrás de la racionalidad y ecuanimidad de nuestra Civilización subyace la voluntad de poder y dominación. Marx sostendrá que el orden pretendidamente universal constituido por la sociedad burguesa esconde y protege los intereses de una clase particular. 
Es difícil determinar el grado de influencia que todos estas ideas pudieron haber tenido en la obra de Kafka, porque sus huellas están bastante ocultas. Su obra tiene, como hemos dicho, el carácter de una imagen en negativo, por lo que es muy difícil encontrar en ella rasgos en positivo de alguna visión utópica a la que se suscribiera. Lo que sí queda evidenciado en su obra es la desolación y pérdida de libertad de sus personajes, así como su creciente sentido de extrañeza frente a sí mismos.

\section{El mundo literario de Praga}

En vida de Kafka, Praga era la capital de la cultura checa, aunque también había allí circuitos culturales alemanes vinculados a dos grandes centros: Berlín y Viena. La posición de Praga frente a estas dos metrópolis era, sin embargo, periférica. Los grandes movimientos artísticos que estaban transformando el arte y literatura sucedían a distancia, y la actitud de los artistas praguenses era mimética y provinciana.

El alemán coloquial de Praga se separaba significativamente de la norma del alemán culto. Además de la fragmentación dialectal bastante acusada en el mundo germánico, se añadía el contacto con lenguas extranjeras, lo cual daba al dialecto praguense un carácter peculiar ${ }^{8}$. Esto evidentemente restaba prestigio a quienes intentaban ingresar al mundo de las letras y la cultura, por lo que algunos autores praguenses exageraban su virtuosismo y recurrían frecuentemente a un lenguaje literario bastante alambicado para demostrar su 'dominio' de la lengua alemana. El mundo literario de lengua alemana de Praga era bastante provinciano y aunque algunos de sus miembros aspiraban a ser reconocidos como autores importantes en el mundo de la germanidad, en realidad, sus famas rara vez trascendían los límites de su ciudad. Excepciones a la regla serían el poeta Rainer María Rilke y Franz Kafka.

Kafka compartía sus inquietudes literarias con un círculo de jóvenes escritores, en su mayoría judíos como él. Además de tratar de mantenerse al día de las últimas manifestaciones en el arte europeo, este grupo de amigos se interesó especialmente por el estudio de la tradición judaica. Aún así es bastante aventurado decir que Kafka participara de un movimiento literario propiamente dicho. Su espíritu era demasiado independiente como para subscribirse a un credo artístico a la manera de los 'ismos' de la vanguardia europea, aunque estuviese seguramente bastante familiarizado con algunos de esos movimientos.

Más de algún crítico sugiere que su obra pertenece al expresionismo, pero además de no existir contactos formales con los exponentes más importantes de esta tendencia, resulta difícil asimilar a este movimiento el elemento místico de la obra de Kafka. Todavía más aventurado y carente de fundamento resulta vincularlo al movimiento surrealista que tendría como centro el París en la déca- 
da de 1920. Los separaba la distancia geográfica, el idioma y el hecho de que la muerte de Kafka coincide con la publicación de los primeros manifiestos surrealistas, por lo que es casi seguro que desconociera totalmente su contenido. Pero tiene más peso a la hora de refutar dicha aseveración la naturaleza de la obra de Kafka. Los surrealistas idearon una serie de experimentos con el afán de romper las fronteras que separaban la obra de arte de la vida cotidiana. La asociación libre, los sueños, la búsqueda de los estados de intoxicación en el momento de creación tienen por objetivo disolver todo control racional en la creación artística y su integración a un modo de experimentar el mundo donde se confunden realidad y representación. Kafka, en cambio, a pesar del carácter alucinante del mundo que evoca su obra, elabora su obra siguiendo una lógica artística muy rigurosa y logrando obras de gran coherencia interna. Poco hay en común entre las cerebrales parábolas kafkianas y la celebración del caos y el azar de los surrealistas.

En definitiva, Kafka marcó distancia frente a los escritores praguenses recurriendo a una lengua literaria de una elegante simplicidad, sin el menor asomo de barroquismos o de localismos. Además, llama la atención la sistemática eliminación de toda alusión al espacio geográfico e histórico concreto. Las obras de Kafka podrían referirse a cualquier sitio. La búsqueda de esta simplicidad en la expresión y la eliminación de las coordenadas geográficas e históricas de su obra apuntan a un intento de recobrar una escritura similar a la de las narraciones bíblicas y los relatos tradicionales judíos. Paradójicamente, será esta cualidad la que permitirá a la obra de Kafka tener una capacidad de resonancia en contextos sociales e históricos diversos y distantes.

II

Para leer "La metamorfosis"

"La Metamorfosis" fue escrita en un momento literariamente muy fructífero de la vida de Kafka. Los diarios de Kafka eluden toda mención al proceso de su escritura; aunque según Max Brod, el autor habría leído el manuscrito a un grupo de amigos el 24 de noviembre de $1912^{9}$. El relato sería publicado hasta tres años después, en 1915. A pesar del juicio favorable de la crítica hacia la obra, Kafka no se encontraba del todo satisfecho con ella. Además de sentirse un tanto avergonzado de haber destilado cuestiones demasiado personales en ella, no estaba contento con la resolución de la trama. Al parecer, había interumpido la redacción del original por algunos días y esto afectaba la coherencia de forma y sentido del relato.

Antes de entrar a discutir la obra, conviene tener en cuenta la controversia 
que hay alrededor del título original y su traducción al castellano y a la mayoría de las lenguas. El original alemán es "Die Verwandlung" que literalmente debería vertirse como "La transformación". En alemán existe un término equivalente a "La Metamorfosis", "die Metamorphose"; sin embargo, Kafka prefirió usar la palabra más sencilla, más próxima al lenguaje coloquial. Las connotaciones que vinculan el título de nuestro relato al proceso físico de cambio de los insectos son, por tanto, enteramente artificiales. Contrario a las mutaciones graduales que sufren algunos animales, la transformación de Gregor Samsa es súbita, inesperada e inexplicada. Igualmente forzada puede resultar cualquier vinculación por el título al clásico latino "Las Metamorfosis" de Ovidio. Todo parece indicar que el autor no las habría tenido en cuenta de manera explícita.

Jorge Luis Borges, célebre escritor argentino y excelente traductor de Kafka al castellano, resume la controversia de la siguiente forma:

"Yo traduje el libro de cuentos cuyo primer título es "La transformación", y nunca supe por qué a todos les dio por ponerle "La metamorfosis". Es un disparate, yo no sé a quién se le ocurrió traducir así esa palabra del más sencillo alemán. Cuando trabajé con la obra el editor insistió en dejarla así porque ya se había hecho famosa y se la vinculaba a Kafka"10

Al parecer las ediciones a las principales lenguas europeas repiten el desacierto denunciado por Borges, por lo que ya no tiene ningún sentido enmendar el error. El nombre de Kafka está unido de manera indeleble a "La Metamorfosis". Sólo nos queda pues, advertir del peligro de incurrir en lecturas equivocadas.

\section{Del estilo}

Tarea ociosa y pedante sería pretender hacer un estudio estilístico de una obra que ha sido vertida de una lengua ajena. Hay quienes sostienen que toda obra literaria pierde de manera irremediable algo fundamental al ser traducida. Esto al parecer se aplica en menor grado a "La Metamorfosis", en particular, y a la obra de Kafka, en general. Pocos son las autores traducidos con tanto éxito a tantas lenguas. Según los entendidos contribuye a ello el estilo conciso, depurado de Kafka. La narración en Kafka es siempre descarnada, distante, por momentos recuerda la fría objetividad de los documentos burocráticos. Sin embargo, el mundo que evocan es un mundo fantástico, alucinado, irreal. Recordemos, si no, el inicio de "La Metamorfosis" donde en unos cuantos trazos se nos refiere como un suceso de lo más normal, el drástico cambio que sufre el protagonista. De ese choque entre la manera de contar y la naturaleza de lo contado surgirá una de las obras más fascinantes y originales de nuestro siglo. 
La estructura de "La Metamorfosis" sorprende por su sencillez y limpieza. Kafka se cuida de utilizar cualquier recurso narrativo extravagante. En lo referente a la instancia narrativa tenemos un narrador en tercera persona, situado fuera del universo del relato. Es típico de la narrativa kafkiana ese "él", objetivo y neutro, que marca una distancia entre el narrador y los personajes. Sin embargo, difícilmente podríamos afirmar que estamos ante el típico narrador omnisciente de la novela realista. El narrador parece comprender tanto o, mejor dicho, tan poco como los personajes. Es incapaz de darnos cuenta de las razones de la transformación y, en la mayoría de los casos, se limita a referir lo acontecido desde la óptica de alguno de los personajes. De hecho, la perspectiva privilegiada en la mayor parte de la obra es la del propio Gregor, aunque intermitentemente el narrador nos transfiera a la perspectiva de los otros miembros de la familia Samsa. Hacia el final, después de la muerte de Gregor, el narrador se sitúa por encima de los personajes y concluye el relato desde una visión más amplia.

En lo referente a la organización temporal, esta es claramente lineal, se nos presentan escasas retrospecciones, pero todas ellas son breves paréntesis al hilo argumentativo principal. El relato está dividido en cuatro apartados sin título. El paso de uno a otro supone una cierta elipsis temporal, es decir, la condensación del paso del tiempo. Sin embargo, lo que anima el dinamismo al relato es, en primer lugar, la ruptura radical de la cotidianidad de Gregor y su familia que supone la transformación del primero. Ello marca un antes y un después de manera brutal. El transcurso del relato refiere pues la ruptura de cierta normalidad de la familia Samsa y la instauración de un nuevo estado, de una nueva normalidad. La transformación de Gregor rompe la primera normalidad y su muerte, por otra parte, da paso a un nuevo estado de cosas.

Ahora bien, en este tránsito se da un proceso. Este proceso está marcado, desde la perspectiva de Gregor, por el súbito aislamiento de Gregor y sus infructuosos intentos por restablecer sus nexos de comunicación con la familia. Gregor sufre del rechazo de sus padres, pero al final, incluso su hermana, quien habría mostrado alguna simpatía por su condición lo termina rechazando. Por otra parte, desde la perspectiva de la familia, el proceso del relato sufre un camino distinto, casi diríamos opuesto. Al principio, dependende totalmente de Gregor. Recordemos que antes de la transformación, Gregor ha asumido la carga de la familia y, sobre todo, la deuda de la quiebra del negocio de su padre. En la medida que Gregor queda imposibilitado para salir al mundo, la familia tiene que ingeniárselas para sobrevivir. Paulatinamente descubren que son capaces de hacerlo y, al final, a la muerte de Gregor han aceptado una nueva normalidad, con menos pretensiones de estatus, pero que les permite asumir el reto del futuro. 
Este movimiento de Gregor hacia dentro y de la familia hacia afuera aparece replicado en los espacios donde se desenvuelve el relato. Parte de la atmósfera asfixiante del relato se debe a que casi todo él transcurre en espacios cerrados, en un juego entre la habitación de Gregor y el resto de la casa. Gregor hace intentos de incursionar el espacio de la casa, pero es repelido violentamente por su padre. Al final queda confinado a la habitación donde muere. Con su muerte, el narrador nos saca a la calle con la familia de Gregor donde asistimos a los planes que tienen para el futuro.

\section{Sobre el sentido}

Hemos resaltado algunos trazos que nos dan una idea de como está organizado el relato. Corresponde ahora tratar de establecer un sentido al relato, es decir tratar de elaborar un propuesta que pueda reducir de manera interesante, aunque provisoria, el infinito caudal significativo del relato. Una manera de entrar puede ser tratar de desentrañar el sentido del simbolismo de la transformación de un ser humano en insecto. Advierto que un símbolo literario no tiene un sentido unívoco, sino, por el contrario, deriva su riqueza de la capacidad de condensar varias significaciones.

En algún pasaje de su "Carta al Padre", Kafka manifiesta que al lado de su progenitor muchas veces se sintió como un insecto, como un ser insignificante. Tendríamos pues un primer sedimento de significación que sería biográfico. El sentimiento de insignificancia del autor frente a su padre y otras fuentes de autoridad que le tocó enfrentar en su vida. En el relato, el insecto aparece como fuente no sólo de insignificancia, sino de repulsión y, sobre todo, de vergüenza. La transformación de Gregor cubre a su familia de ignominia. Ni el padre, ni la madre, ni la hermana son capaces de ver a Gregor directamente sin dar muestras de repugnancia. Aparece aquí un nuevo elemento, el estigma social.

Para Gregor, sin embargo, la condición de insecto significa sobre todo una incapacidad total de comunicarse. Su cuerpo no le responde, no es capaz de articular su voz. A su interior, Gregor sigue siendo el mismo, pero su cuerpo le es ajeno y, peor aún, un obstáculo para interactuar con los demás. Gregor queda pues reducido a su pura interioridad, literalmente encerrado dentro de su caparazón de insecto. Gregor amanece pues un día prisionero de su caparazón. Sin embargo, no se puede decir que antes de la transformación fuese más libre. Antes de la transformación Gregor se encontraba prisionero de una rutina asfixiante: de un trabajo que le disgustaba y le exigía demasiados sacrificios, pero sobre 'todo de una obligación con la familia. La transformación lo que habría hecho es volver literal una condición que se podría decir que era metafórica. Gregor aprisionado por deudas, por obligaciones, privado de libertad, queda reducido a la condición de insecto. 
Como antes mecionamos, José María González nos llama la atención de la coincidencia de esta visión de la condición humana de Kafka con la de su casi contemporáneo Max Weber. Para éste último, la sociedad tecnificada y burocratizada moderna se ha convertido en una 'jaula de hierro' para el individuo. Es decir, la dominación de la naturaleza y la organización racional del trabajo que deberían contribuir a la realización del ser humano, se revierten en su contra y se vuelven en una prisión imposible de romper. La coincidencia se acentúa más, si tenemos en cuenta que el vocablo "Gehäuse" que usualmente se ha vertido como "Jaula", puede traducirse también como "Coraza". Así, la imagen de la "jaula de hierro" [stahlhartes Gehäuse] podría entenderse como la visión del alma del hombre aprisionada por una "coraza de hierro". En el terreno de la creación imaginativa, Kafka hizo uso de metáforas similares para recrear la miseria de su época. Aunque ambos autores no trabaran un contacto directo, es evidente que dan cuenta de algo que forma parte del espíritu de su época.

En otro pasaje de su obra, Kafka suscribe de manera bastante explícita la visión de Weber sobre el individuo en la sociedad capitalista avanzada:

"El animal arranca el látigo de la mano de su amo y se azota por su cuenta para convertirse en amo de sí mismo, y no sabe que eso es únicamente fantasía, nacida de un nuevo nudo de la correa del látigo del dueño".

Sin embargo, pese a las apariencias hay razones para sospechar que la visión de mundo de Kafka no es totalmente fatalista. Al menos el relato nos elementos para ello. Desde cierta perspectiva, podría verse el proceso que sufre Gregor como un sacrificio en el que tanto él como su familia terminan siendo redimidos. En primer lugar, tenemos la cuestión de la deuda. Con la transformación de Gregor la familia queda exonerada de la deuda contraída por el padre y que pesaba sobre todos ellos. Pero también, en segundo lugar, la transformación altera radicalmente la dinámica familiar. Poco a poco, en la medida en que caen en la cuenta de que ya no disponen de Gregor para vivir de acuerdo a las expectativas sociales, van cobrando confianza en sus propias fuerzas y se dan cuenta que tienen todavía esperanzas de enfrentar la pobreza con dignidad y hasta alegría. La transformación y posterior muerte de Gregor es un verdadero sacrificio, en el que tanto él como su familia salen ganando. Gregor queda liberado de una existencia rutinaria y miserable. La familia se reencuentra a sí misma y descubre que una vida sencilla, de colaboración y de trabajo tiene sus retribuciones. Lo trágico de todo es, sin embargo, que Gregor ya no tiene lugar en este nuevo arreglo, que su exceso de meticulosidad y autoconciencia lo llevan a un autismo estéril.

Se ha hablado de mucho de los elementos de la vida personal y familiar de Kafka que aparecen en el relato. Ello es innegable. Gregor tiene mucho de Franz; la hermana, de Ottla; el padre, de Hermann; y la madre, de Julie. Sin embargo, no hay que perder de vista que el relato introduce variantes que no 
deben ser pasadas por alto, variantes que son significativas. Gregor es un ser mucho más desvalido y anodino que Franz, entre otras razones porque carece de inclinaciones artísticas. El padre de Gregor, a diferencia del padre de Franz, ha fracasado en su empresa. La hermana de Gregor flaquea en su lealtad, a diferencia de Ottla que siempre estuvo de lado de su hermano. Es evidente, que Kafka está queriendo llevar a ciertos extremos su drama familiar. Para Kafka su vida familiar era manifestación de la inautenticidad de su tiempo, de cadenas autoimpuestas por prejuicios, convenciones, expectativas irreales. La única vía que quedaba abierta era la búsqueda de una vida más sencilla, más auténtica, más fundada en la solidaridad y menos en obligaciones impuestas desde fuera.

1. El autor desea expresar su gratitud al Dr. José María González García cuyo libro La máquina burocrática (Afinidades electivas entre Max Weber y Kafka, Madrid: Visor, 1987), expuesto en un seminario impartido en la Universidad Centroamericana José Simeón Cañas (UCA) durante los meses de febrero y marzo de 1994, fue de incalculable utilidad para elaborar el presente ensayo.

2. Benjamin, Walter. "Dos iluminaciones sobre Kafka" en Imaginación y sociedad. Iluminaciones I. Madrid: Taurus, 1988. Pp. 203-204.

3. Apud Anderson, Mark. "Introduction" en su edición de la colección de ensayos Reading Kafka. Prague, politics and the fin de siècle. Nueva York: Schocken Books, 1989. Pp. 18.

4. "Sobre la cuestión de las leyes", apud. González García, Op. Cit., p. 81

5. Apud. González García, Op. cit. Pp. 48-49.

6. Sobre la relación entre Kafka y el nacionalismo judío he consultado a Stölzl, Christoph. "Kafka: Jew, Anti-Semite, Zionist" en Anderson, Mark (ed.) Reading Kafka...

7. Kurz, Gerhard. "Nietzsche, Freud and Kafka" en Anderson, Mark (ed.) Op. cit. Pp. 143 y ss.

8. Wagenbach, Klaus. "Prague at the Turn of the Century" en Anderson, Mark (ed.) Op. cit.

9. Brod. Max. Kafka. Madrid: Alianza, 1982, p. 126.

10. Apud. Jordi Llovet, "Introducción", en Franz Kafka, La metamorfosis y otros relatos, Barcelona: España, 1992, p. ix.

11. Apud. González García, Op. Cit., pp. 94-95. 